\title{
Formação de grupos internacionalizados com apoio do BNDES e seus impactos na economia brasileira
}

\author{
Armando Dalla Costa \\ André Eduardo Iurk ${ }^{* *}$
}

\begin{abstract}
Resumo: O objetivo do presente trabalho é analisar o recente período de mudanças na economia no que tange as fusões e aquisições (F\&A) realizadas por parte de empresas brasileiras com suporte do Estado. A formação de grandes empresas encontrou no BNDES o apoio para seus investimentos e com isso o banco apresentou uma crescente participação na economia nos últimos anos. Para atingir o objetivo, será realizada uma abordagem teórica baseada na teoria evolucionária da firma, assim como sobre a competição tratando dos dois agentes envolvidos nesta política (firma e Estado). Em seguida será apresentado o papel do BNDES e qual foi a evolução histórica de seus indicadores, passando para uma análise da estratégia do governo e quais os ganhos específicos pretendidos. Por fim, serão apresentados os resultados da economia brasileira nos anos em que ocorreram estas transformações, buscando demonstrar o resultado desta política.
\end{abstract}

Palavras-chave: Fusões e aquisições; BNDES; Inovação; Teoria evolucionária; Competição; Economia brasileira; Internacionalização.

Classificação JEL: F2, G20, L22.

\footnotetext{
" Doutor pela Université de Paris III (Sorbonne Nouvelle) e Pós-Doutor pela Université de Picardie Jules Vernes, Amiens. Professor no Departamento de Economia e no Programa de Pós-Graduação em Desenvolvimento Econômico da Universidade Federal do Paraná. Líder do Núcleo de Pesquisa em Economia Empresarial (www.empresas.ufpr. br) e presidente da Associação Brasileira de Pesquisadores em História Econômica, gestão 2011-2013. Endereço eletrônico: ajdcosta@ufpr.br

** Graduado em Economia pela Universidade Federal do Paraná. Endereço eletrônico: andre.ed@gmail.com
} 


\section{Introdução}

O Brasil passa por uma nova fase no desenvolvimento econômico. Segundo documento elaborado pelo Ministério do Planejamento, como orientação estratégica para atuação do governo Lula no período de 2008 a 2011 (OEG do Plano Plurianual 2008 - 2011), uma das metas gerais foi "Elevar a competitividade sistêmica da economia, com inovação tecnológica". Para tanto, o governo Lula adotou uma política de incentivo à formação de grandes grupos empresariais para se tornarem competitivos no mercado internacional.

Pode-se admitir como alguns exemplos dessa medida casos como a Fusão da Brasil Telecom e a Oi; Sadia e Perdigão; Aracruz Celulose e Votorantim Celulose; JBS Friboi e a Bertin; TOTVS e Datasul e a incorporação da Quattor pela Brasken. (Instituto Alvorada, 2010).

A adoção destas políticas por parte do governo, apesar de ações não conectadas, teve papel fundamental na evolução das firmas brasileiras, provocando por um lado a necessidade de mudanças no funcionamento das empresas, e de outro, consolidando empresas com bases cada vez mais competitivas. Neste sentido, um novo movimento no desenvolvimento é a política de incentivo a criação de grandes grupos econômicos com a finalidade de se internacionalizarem.

Os principais motivos apresentados pelo governo para ser um incentivador da internacionalização estão dispostos no médio e longo prazo, onde empresas globais e competitivas podem gerar no país empregos de maior qualificação, desenvolver tecnologias e inovações internamente, abrir espaço para mais exportações, e com subsidiárias no exterior, o país pode contar com uma remessa de lucros inversa ao modelo atual, onde as empresas no Brasil remetem lucros ao exterior. Além disso, podem-se contar os benefícios que as empresas geram em sua cadeia de fornecedores e na relevância do país em fóruns internacionais.

Na criação de conglomerados industriais, a atuação do governo ocorre em diferentes graus de significância, sendo os principais instrumentos a autorização prévia da agência reguladora, posterior aprovação do Conselho Administrativo de Defesa Econômica - CADE, concessão de estímulos financeiros por meio de empréstimos do BNDES e também via oferta de participações societárias (Instituto Alvorada, 2010).

O objetivo deste trabalho é analisar o novo passo do desenvolvimento do país com o apoio do BNDES na formação de grandes conglomerados, destacando como ele utilizou e utiliza seus recursos para apoiar a internacionalização das empresas brasileiras, fundamentando a política em uma base de desenvolvimento das firmas. Primeiro, serão apresentadas algumas teorias que tratam do crescimento da firma buscando a fundamentação da relação entre a política adotada pelo governo e seus objetivos, e posteriormente serão apresentados os efeitos da política sobre a economia brasileira evidenciando os resultados alcançados. 


\section{Referencial teórico}

Esta seção tem o objetivo de apresentar as teorias econômicas que podem servir de base para análise e fundamentação da política de incentivo à criação de grandes grupos e a internacionalização. $\mathrm{O}$ foco do referencial utilizado trata dos conceitos do crescimento e desenvolvimento das empresas e da competição, pois está nas firmas a decisão de uma estratégia de crescimento.

\subsection{Teoria evolucionária}

Nelson e Winter (2005) consideram que a propensão a inovar é a verdadeira base para o crescimento da firma, relegando importância secundária para as economias de escala e escopo. $\mathrm{Na}$ análise, os autores elencam os lucros como incentivadores da atividade inovadora e esta como fator predominante no crescimento das firmas, criando maior crescimento com inovações bemsucedidas e com maior grau de inovação.

Nesta teoria, com bases originadas e definidas por Schumpeter, a inovação tecnológica é o fator responsável pelo crescimento, gerando a heterogeneidade entre as firmas que passam sobre o processo de seleção por parte do mercado, onde nem todas terão a mesma chance. Diante disto, temos que existe uma concorrência inicial pela sobrevivência das empresas, e o sucesso de uma ou mais corrobora para o fracasso de outras.

Desta forma, as empresas inovam de acordo com suas estratégias e necessidades. No grupo de firmas inovadoras os autores destacam dois principais subgrupos, os que lideram as inovações tecnológicas do seu mercado e os que copiam as tecnologias lançadas pelos líderes. Mostra-se então a necessidade de possuir uma estratégia adequada para o crescimento das firmas que de um lado possuem a liderança das inovações tecnológicas, que podem agregar muito ao desenvolvimento, mas possuem necessidade de investimentos mais elevado,s e do outro, existe a possibilidade de se tentar acompanhar os líderes do mercado incorrendo em menores custos (Nelson e Winter, 2005).

O principal motivo que leva parte das firmas a tentarem tomar a liderança nas inovações é a intenção de obter vantagens com a exclusividade de determinada tecnologia, podendo até gerar um poder monopolista. Mesmo que de caráter temporário, o processo de inovação deve agregar à firma conhecimentos que podem gerar retornos dinâmicos no longo prazo, incrementos de conhecimento para estratégias futuras e aumento na acumulação interna de fundos.

De acordo com os mesmos autores, com essa característica de inovação movida pelo lucro e a existência de um processo seletivo na sobrevivência das firmas, existe uma tendência de desenvolvimento de concentração. Principalmente em um cenário em que as empresas tentam tomar a frente na inovação, já que a recompensa para as empresas com inovações bem-sucedidas são os lucros que lhes permitem ser mais competitivas no campo de pesquisa e desenvolvimento. Para um país ou setor em que as empresas se preocupam 
mais em copiar tecnologia, produtos ou processos inovadores já aprovados no mercado, a tendência de concentração é muito menor (Nelson e Winter, 2005).

Relacionando os conceitos desta teoria à ação de incentivos do governo, podemos dizer que o governo atuaria em suas metas de promover a inovação tecnológica e ganhar competitividade em um cenário globalizado, prezando também pela sobrevivência das empresas nacionais. Além disso, a teoria sinaliza que existe uma tendência forte a concentração de mercado quando as empresas se dispõem a liderar o mercado.

\subsection{A decisão de incentivo}

Possas (1984) afirma que o poder de controle de mercado e os ganhos oligopolísticos são condição ou tendência das empresas como desfecho e motivação básica do processo de inovação. Destacando as características que conectam a concentração, as barreiras a entrada e a lucratividade, o autor propõe que as empresas estarão atuando com dois limitadores condicionantes das margens de lucro. Como limitador máximo, a formação de barreiras a entrada, e como limitador mínimo, as restrições financeiras da firma. Desta forma, o preço será afetado pelas novas estruturas de mercado originadas.

Na teoria evolucionária também observamos que as firmas devem buscar o crescimento na inovação. Havendo incentivo, disponibilidade de recursos e abertura para investimentos, estarão realizando estratégias para investir em busca do seu crescimento e um ponto central está ligado às inovações. Fazendo isto, se espera que as empresas estejam demandando e provocando um desenvolvimento maior do que o que compete a apenas elas, mas engloba toda a sociedade.

Então as firmas não se tornarão mais competitivas apenas pelos investimentos ou aumento do seu porte via fusões e aquisições, mas sim por um movimento complexo interno e externo incluindo o desenvolvimento de diversas necessidades a partir de diferentes incentivadores. Espera-se, então, que estas empresas mais competitivas demandem, para sua crescente expansão, recursos humanos em maior quantidade e com maior especialização, que ocorram maiores investimentos no desenvolvimento de melhores tecnologias e práticas de P\&D, um aumento da sua diversidade e quantidade de produção, demandem melhorias de infraestrutura, entre outros benefícios como os impactos que afetam toda a sua cadeia de fornecedores e toda a rede social ao redor destas empresas.

Objetivando este maior desenvolvimento, é discutido se o Estado deve ou não atuar no mercado influenciando e induzindo as empresas para algum caminho específico.

Para Porter (1999), a atuação dos governos não deve ser direcionada a favor da visão do livre mercado, mas também não deve ser direcionada como promotor imprescindível dos setores estratégicos ou prioritários. Sendo que um Estado não ativo estaria perdendo oportunidades de criar um ambiente estimulante para conquista de vantagens competitivas, enquanto um Estado excessivamente ativo na estratégia de apoiar o crescimento das empresas iria 
criar no longo prazo empresas dependentes.

Referente ao apoio do governo o autor afirma:

O papel apropriado do governo é o de catalisador e desafiante, consiste em encorajar - ou até mesmo impelir - as empresas a elevar suas aspirações e a galgar níveis mais altos do desempenho competitivo, ainda que o processo seja intrinsecamente desagradável e difícil. O governo não é capaz de criar setores competitivos; essa tarefa compete apenas às empresas (Porter, 1999, p.197).

O governo deve agir no papel de incentivo às empresas, controlando o mercado para não gerar situações excessivamente de monopólio, pois com o poder as empresas tenderão a criar barreiras para entrada de concorrentes e estabelecer fixação de preço, e como consequência disto haverá menor ou nenhuma rivalidade. Além do que, não haverá incentivos a inovações, portanto, é preferível para o Estado e a sociedade, que a expansão se dê por meio de aquisições de firmas no exterior do que fusões no ambiente doméstico e que a nacionalidade da empresa "sobrevivente" seja brasileira.

\section{O BNDES}

A presente seção tem o objetivo de contextualizar a história da instituição, sua orientação de trabalho e os principais números do banco, dados que nos fornecem informações importantes em relação a seu trabalho realizado no financiamento das empresas brasileiras.

\subsection{A história do banco}

Empresa pública federal ${ }^{1}$ com o objetivo de incentivar o crescimento do país principalmente através da industrialização de empresas nacionais, esteve presente ativamente nos períodos de substituição de importações e abertura comercial, caracterizando-se pelo apoio à agricultura, indústria, infraestrutura, comércio e serviços, através de financiamentos a projetos de investimentos, aquisição de equipamentos e exportação de bens e serviços.

O banco é hoje o principal instrumento de financiamento de longo prazo para a realização de investimentos em todos os segmentos da economia, visando uma política que inclui as dimensões social, regional e ambiental (BNDES, 2012).

Em seu planejamento corporativo vigente, o BNDES tem como objetivo alavancar a inovação, o desenvolvimento local e regional e o desenvolvimento socioambiental, através de financiamentos a projetos de investimentos, aquisição

\footnotetext{
1 Fundada em 1952 no governo Vargas, inicialmente intitulado de BNDE (Banco Nacional do Desenvolvimento Econômico), recebeu mais uma atribuição que foi acrescentada ao nome em maio de 1982 e passou a ser intitulado de Bando Nacional do Desenvolvimento Econômico e Social - BNDES.
} 
de equipamentos e exportação de bens e serviços (BNDES, 2012).

\subsection{Origem dos recursos}

O banco possui basicamente seis fontes de recursos para desempenhar suas funções de financiamento, das quais se destaca a proporção advinda de recursos governamentais que somaram em 2011 um total de 81,7\% de toda sua estrutura.

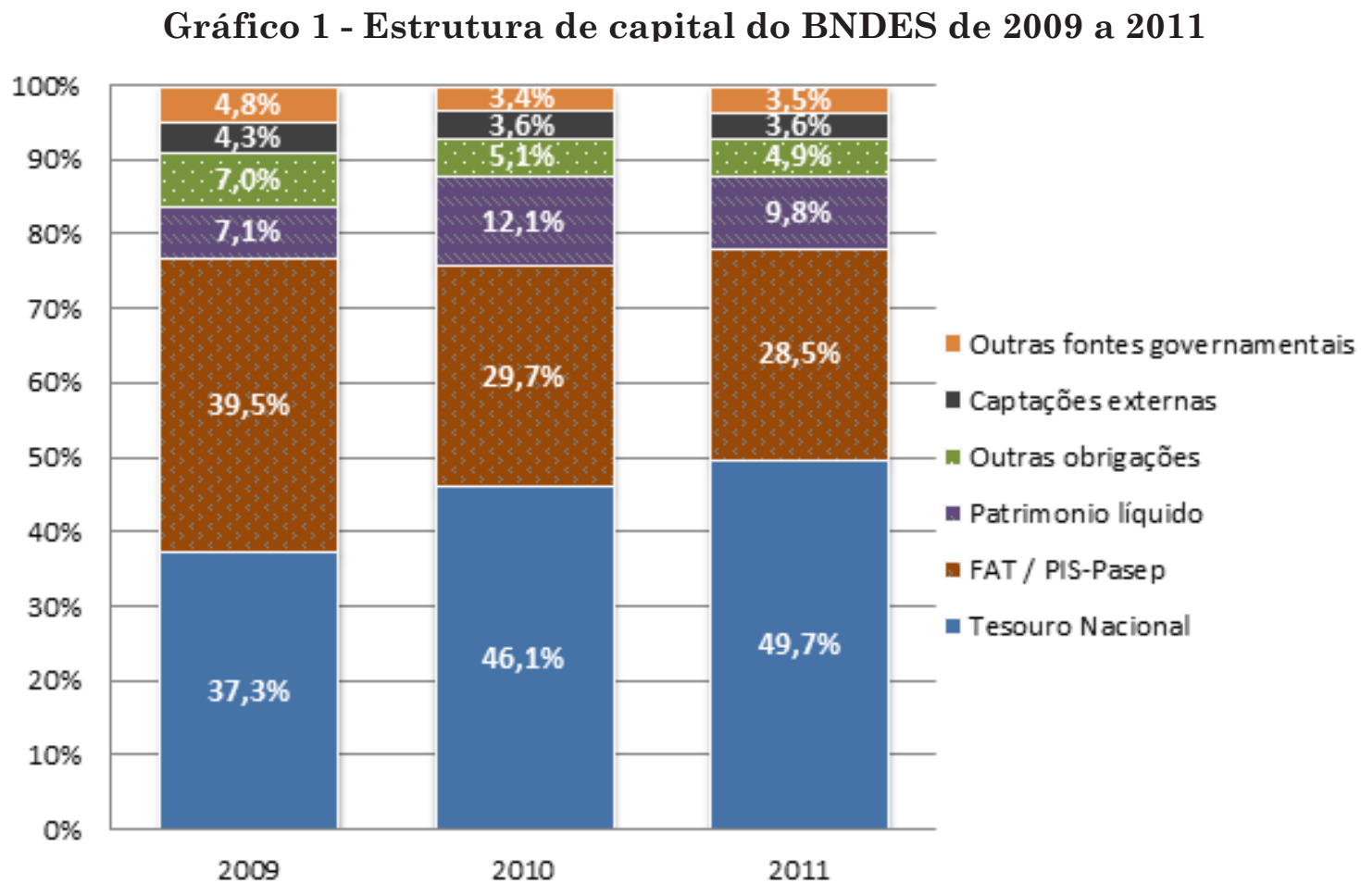

Fonte: BNDES (2011)

Conforme apresentado no Gráfico 1, destacam-se como fontes de recursos o Tesouro Nacional e o Fundo de Amparo ao Trabalhador (FAT / PIS-Pasep). Em função das características das fontes de recursos, temos que a instituição possui o compromisso de trabalhar a favor do Estado e da sociedade, apoiando o desenvolvimento das empresas, mas com objetivo de promover a nação.

\subsection{Plano Corporativo 2009-2014}

O BNDES possui um Planejamento Corporativo formulado com o objetivo de definir as diretrizes de atuação e a estratégia do Banco para o período de 2009 a 2014. Segundo estas diretrizes, sua missão deverá ser de promover o desenvolvimento sustentável e competitivo da economia brasileira, com geração de emprego e redução das desigualdades sociais e regionais.

Deacordocomoplano, as empresas quebuscam recursos parainvestimento 
do BNDES precisam ser avaliadas de forma ampla e não focada apenas em seu projeto, considerando a estratégia competitiva de crescimento da empresa, capacidade de gestão, inovação e de se manter competitiva. Além disso o banco leva em conta, em relação às firmas, sua responsabilidade social corporativa, a geração de empregos provocada, sua influência sob o desenvolvimento regional e local e sua possibilidade de inserção no mercado internacional por meio de exportação ou de investimentos externos, portanto toda extensão do impacto do possível investimento no desenvolvimento brasileiro. Isto significa que há uma mudança nos procedimentos de avaliação de crédito, considerando não somente os ativos tangíveis mas, principalmente, os ativos intangíveis - as competências - das empresas que, na realidade, constituem o sustentáculo de sua sobrevivência nos mercados (Ramalho, Café e Costa, 2008).

Também se situa como objetivo pretendido a ação de fortalecer e valorizar uma estrutura diversificada da economia brasileira, respeitando cada setor ou empresa em seu estágio de desenvolvimento atual, fortalecendo tanto as empresas que ainda necessitam evoluir para competir no mercado interno quanto as que já têm forças para buscar a inserção no mercado internacional ou até brigar por uma posição de liderança mundial, visando à evolução de várias frentes ao sucesso, garantindo sempre as melhores práticas competitivas no mercado globalizado.

Restringindo o foco aos grandes grupos que cresceram e já adotaram uma estratégia de internacionalização e diversificação de mercados, para estes grupos manterem ou brigarem por posições de lideranças, necessitarão de apoio para seu contínuo crescimento, atribuindo ao BNDES os desafios de realizar o suporte à exposição ao risco e aumento da capacidade de investimento.

Para a realização de todo este trabalho, o BNDES previu um aumento do porte do banco. Entre os anos de 2007 e 2009, houve a ampliação dos ativos de $\mathrm{R} \$ 203$ bilhões para $\mathrm{R} \$ 309$ bilhões com um crescimento de $52,4 \%$, e encerrou em 2011 com $\mathrm{R} \$ 624$ bilhões em ativos, com um crescimento de 207,4\% em relação a 2007 (BNDES, 2011).

Conforme citado por Ramalho, Café e Costa (2010, p. 101):

[...] além da garantia de recursos para o desenvolvimento brasileiro, como em toda instituição financeira, as orientações estratégicas do BNDES atentam para a importância do aperfeiçoamento das metodologias de avaliação e precificação de risco de projetos e empresas essa orientação é fundamental para ampliar o acesso ao crédito.

\subsection{Aplicação dos recursos}

Recentemente o banco vem aumentando sua participação na economia brasileira, obtendo recordes sucessivos. Em 2010, com o maior valor já desembolsado em sua história, chegou a 168,4 bilhões, e em 2011 com um total de 896 mil financiamentos, atingiu o valor de $\mathrm{R} \$ 139,7$ bilhões de desembolso 
em financiamentos.

No Gráfico 2 podemos ver a evolução dos desembolsos realizados por parte da instituição.

Gráfico 2 - Total de desembolso do BNDES em R\$ Bilhões

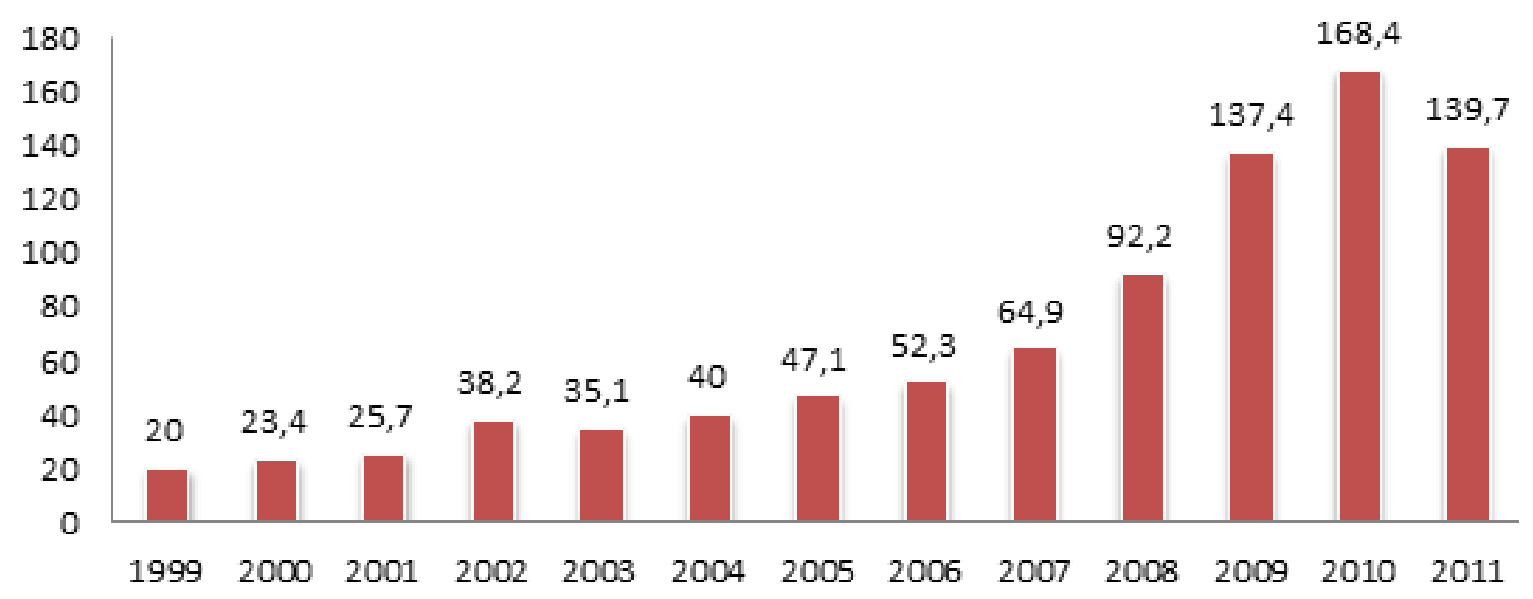

Fonte: BNDES (2011)

Dentro da atual política crescente de valores desembolsados podemos avaliar o destino dos investimentos. Em relação ao tamanho das empresas financiadas, o BNDES classifica seu porte como sendo consideradas grandes as que possuírem receita operacional bruta anual superior a $R \$ 300$ milhões e abaixo deste valor são classificadas como sendo Micro, Pequena, Média ou Média Grande (MPME).

No Gráfico 3 é apresentado o montante destinado as grandes empresas e as empresas classificadas como MPME.

Gráfico 3 - Desembolso por porte de empresa em R\$ Bilhões

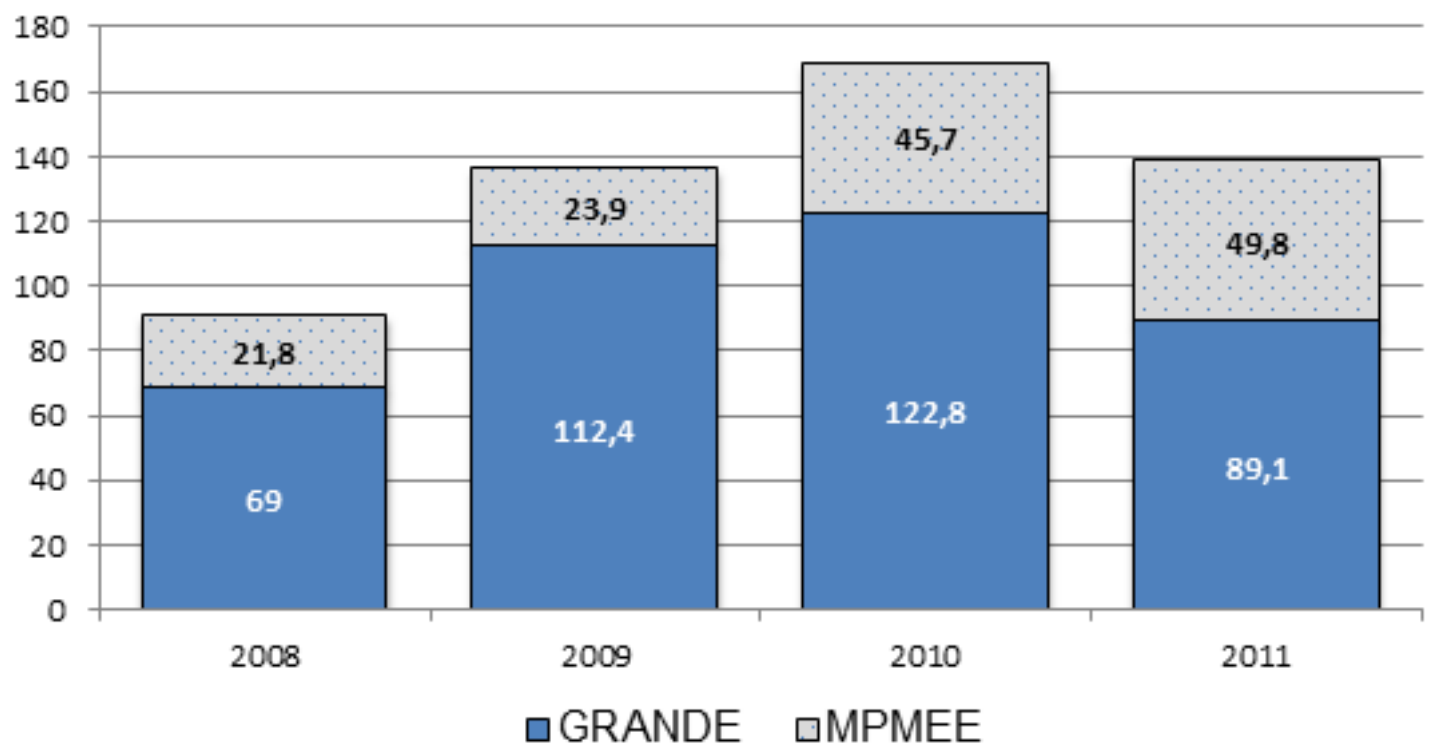

Fonte: BNDES (2011) 
Podemos ver que o maior crescimento ocorreu em 2009 com um aumento de aproximadamente 50\% no valor desembolsado pelo banco. Dentro deste valor, destacou-se o destino as grandes empresas, com taxa de crescimento de $62 \%$ contra 10\% no ano (para MPMEE).

Ao longo do período dos quatro anos apresentados, o desembolso total foi de 524,5 bilhões de reais, e 74\% do valor total teve como destino as grandes empresas.

Também se fazimportante destacar o ramo de atividade dos investimentos dos últimos anos. A Tabela 1 apresenta os valores e as taxas de crescimento do financiamento por ramo de atividade:

Tabela 1 - Desembolso por ramo de atividade de 2008 a 2011

\begin{tabular}{|c|c|c|c|c|c|c|c|}
\hline & \multicolumn{4}{|c|}{ (em R\$ Bilhões) } & \multicolumn{3}{|c|}{ Taxa de crescimento (\%) } \\
\hline Ramo de atividade & 2008 & 2009 & 2010 & 2011 & 2009-2008 & $2010-2009$ & $2011-2010$ \\
\hline Indústria & 39 & 63,5 & 54 & 43,8 & 62,8 & $-15,0$ & $-18,9$ \\
\hline Infraestrutura & 35,1 & 48,7 & 52,4 & 56,1 & 38,6 & 7,80 & 7,0 \\
\hline Comércio/serviços & 11,2 & 17,3 & 27,1 & 29,2 & 55,2 & 56,4 & 7,7 \\
\hline Agricultura & 5,6 & 6,9 & 10,1 & 9,8 & 22,5 & 47,7 & $-3,2$ \\
\hline Outras oper. de mercado & 1,4 & 1 & 24,8 & 0,8 & $-23,4$ & 2275,7 & $-96,8$ \\
\hline Total & 92,2 & 137,4 & 168,4 & 139,7 & 49,0 & 22,6 & $-17,1$ \\
\hline
\end{tabular}

Fonte: BNDES (2011).

Conforme apresentado no Gráfico 2, ao longo dos últimos 12 anos, houve um crescimento expressivo de investimentos por parte do BNDES, principalmente nos anos de 2008 a 2012. Nesta linha podemos verificar quais foram os setores alvo destes investimentos.

Segundo dados da Tabela 1, o crescimento foi principalmente focado no setor de comércio e serviços (163\%), seguido por agricultura (75\%) e Infraestrutura (60\%), ficando a menor parcela do crescimento com a indústria, que cresceu apenas $12 \%$ no valor de investimentos.

\section{Estratégia e resultados}

Nesta seção pretende-se demonstrar quais são os motivos que fundamentaram as ações do governo na utilização do BNDES, a poiando a criação e o crescimento de grandes grupos empresariais e quais foram os impactos relacionados a esta ação.

\subsection{Estratégia de desenvolvimento}

A Orientação Estratégica do Governo (OEG do Plano Plurianual 2008 2011) reflete a estratégia de desenvolvimento do governo no longo prazo. Com base nestes objetivos é que devem surgir as ações do setor público (Ministério do Planejamento, 2007). 
A OEG do governo Lula, que contemplou o período 2008 a 2011, considera como características importantes, e que devem ser respeitadas em sua estratégia, a grande dimensão territorial e a qualidade do patrimônio natural, a complexidade e diversidade cultural e a abrangência da matriz produtiva ${ }^{2}$.

É importante ressaltar que existe um aspecto geral entre os 10 objetivos listados, que é o desenvolvimento econômico e social, com redução das desigualdades sociais e regionais de forma que o desenvolvimento seja sustentável no longo prazo.

A ação do Estado como criador de conglomerados possui maior relação com as metas "2) Promover o crescimento com sustentabilidade, geração de empregos e distribuição de renda, 7) Fortalecer a inserção soberana internacional e a integração sul-americana e 8) Elevar a competitividade sistêmica da economia, com inovação tecnológica;". Portanto, estes são pontos relevantes que determinam a coerência entre objetivo estipulado e ação realizada.

Para alcançar esse objetivo o país enfrenta vários desafios, conforme apresentado na OEG. São eles: a) a baixa disponibilidade de crédito; b) a deficiência em processos de captação de recursos humanos competentes por parte das empresas; c) a elevada concentração da produção científica e tecnológica em regiões mais favorecidas pelos investimentos públicos e privados; d) a baixa capacidade das empresas com relação a gestão da tecnologia; e) a baixa articulação entre indústria e instituições de pesquisa; f) a pequena produção tecnológica; g) o baixo investimento privado em pesquisa e desenvolvimento; e h) a baixa proporção de empresas que realizam inovações.

Combinados a estes desafios, os principais motivos apresentados pelo governo para ser um incentivador da criação de grandes empresas internacionalizadas são dispostos no médio e longo prazo, onde empresas globais competitivas podem gerar no país empregos de alta qualificação, desenvolver tecnologias e inovações internamente, abrir espaço para mais exportações e com subsidiárias no exterior o país pode contar com uma remessa de lucros inversa ao modelo conhecido onde as empresas no Brasil remetem lucros ao exterior.

\subsection{Competitividade internacional}

Diante dos objetivos traçados pelo governo, temos um cruzamento direto da criação de grandes empresas com o processo de internacionalização destas, pois é desta forma que se tornarão competitivas e trarão maior relevância para o país.

De acordo com pesquisa realizada em 2012 pela Fundação Dom Cabral

\footnotetext{
2 Os objetivos do governo naquele plano eram os seguintes: 1) Promover a inclusão social e a redução das desigualdades; 2) Promover o crescimento com sustentabilidade, geração de empregos e distribuição de renda; 3) Propiciar o acesso da população brasileira à educação e ao conhecimento com equidade, qualidade e valorização da diversidade; 4) Fortalecer a democracia, com igualdade de gênero, raça e etnia, e a cidadania com transparência, diálogo social e garantia dos direitos humanos; 5) Implantar uma infra-estrutura eficiente e integradora do território brasileiro; 6) Reduzir as desigualdades regionais a partir das potencialidades locais do território nacional; 7) Fortalecer a inserção soberana internacional e a integração sul-americana; 8) Elevar a competitividade sistêmica da economia, com inovação tecnológica; 9) Promover um ambiente social pacífico e garantir a integridade dos cidadãos; 10) Promover o acesso com qualidade a serviços e benefícios sociais, sob a perspectiva da universalidade e da equidade, assegurando-se seu caráter democrático e descentralizado
} 
aos gestores de empresas internacionalizadas, os cinco maiores motivos para as empresas buscarem a internacionalização são, em ordem de relevância: 1) fortalecer sua marca pela presença internacional; 2) aumentar a capacidade de atendimento a clientes globais, 3) diferenciar-se perante concorrentes domésticos ou menos internacionalizados; 4) melhorar a imagem da empresa no mercado doméstico e 5) capacitar-se para potencializar a inovação tecnológica.

Ainda nesta pesquisa, os gestores apontaram em suas opiniões os maiores benefícios que o processo traz para o Brasil, sendo eles, em ordem: 1) melhoria da imagem do país; 2) incorporação de novas tecnologias e processos ao parque industrial brasileiro; 3) fortalecimento da posição brasileira em negociações nos fóruns internacionais, regimes internacionais e OMC; 4) servir como antídoto à desnacionalização de setores da economia brasileira; e 5) Internacionalização de PMEs da cadeia de valor das grandes empresas.

Conforme observação de Alem e Madeira (2010, p.51):

No Brasil, até recentemente, o apoio à criação de multinacionais brasileiras não era considerado uma prioridade da política econômica. Os principais movimentos de internacionalização foram feitos pelas próprias empresas. Crescentemente, entretanto, a questão tem assumido destaque na pauta do governo, e um sinal dessa mudança estratégica tem sido o apoio à formação de grandes grupos nacionais, por meio de fusões e aquisições.

Evidência de que o processo de internacionalização das empresas vem ocorrendo e aumentando está no crescente aumento do estoque de investimento externo direto (IED) partindo de empresas brasileiras. Conforme Gráfico 4, o país ficou, entre os anos de 1981 a 2005, com estoque médio próximo aos 50 bilhões de dólares, e a partir de então manteve um crescimento, ultrapassando os 200 bilhões em 2011. Há então um crescimento conjunto do valor de desembolsos do BNDES e do valor de estoque brasileiro nos anos de 2007 e 2011.

Gráfico 4 - Estoque de IED brasileiro de 1981 a 2011 em U\$ Milhões

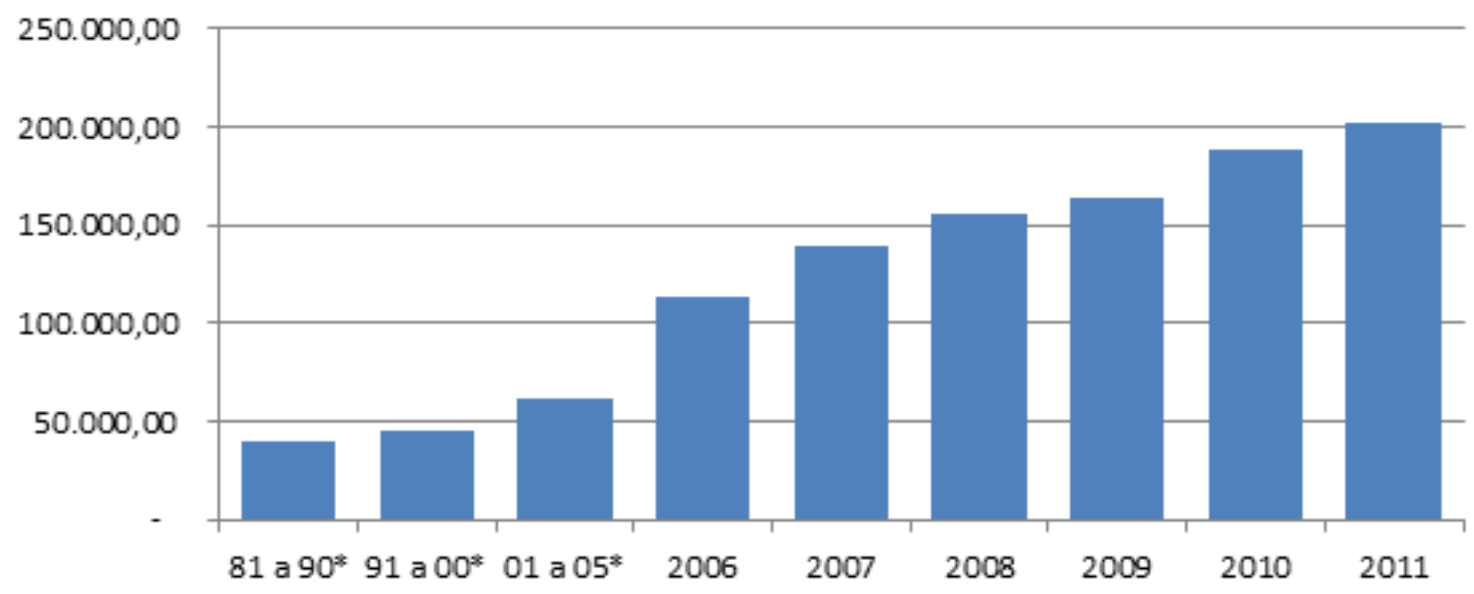

${ }^{*}$ Média ano do período.

Fonte: Elaboração própria. Dados de Unctad, UNCTADSTAT (2012). 
Em uma economia globalizada, os resultados das firmas nacionais nos mercados estrangeiros são cada vez mais importantes para a performance do país. Com a competição nos mercados internacionais, as empresas devem promover o desenvolvimento do seu país de origem, facilitando o acesso a mercados e recursos.

Segundo Alem e Cavalcanti (2005, p. 8):

[...] o acesso a mercados maiores fortalece a competitividade das empresas multinacionais pelas economias de escala, por meio dos efeitos de especialização de aprendizado e pelo fornecimento de uma maior base financeira para reinvestimentos e desenvolvimento tecnológico.

$\mathrm{Na}$ história econômica internacional observam-se importantes relações entre investimentos no exterior, comércio internacional e fluxos de tecnologia, evidenciando a importância da internacionalização como forma de desenvolvimento das empresas (Alem e Cavalcanti, 2005).

Em relação às empresas internacionalizadas, sua dispersão geográfica das atividades também deve influenciar nas atividades de $P \& D$, pois as firmas terão maior acesso às tecnologias estrangeiras e também, com uma maior escala de produção, poderão diluir os custos com P\&D (Alem e Cavalcanti, 2005).

Dias, Caputo e Marques (2012) analisaram os impactos nacionais decorrentes das empresas que investiram no exterior. $\mathrm{Na}$ análise foram observadas seis empresas que receberam apoio financeiro do BNDES, através da Linha de Internacionalização de Empresas, produto que possui a intenção de promover a inserção e o fortalecimento de firmas de capital nacional no mercado internacional. As empresas foram: Bematech, Braskem, Eurofarma, Marfrig, Metalfrio e WEG.

Através de pesquisa com executivos envolvidos no processo de investimentos e dos relatórios anuais das empresas, os autores listaram os principais motivos e resultados deste processo.

Como motivações para ampliar os negócios, destacaram-se entre os casos analisados a busca por novos mercados e a busca por novas tecnologias. $\mathrm{O}$ acesso a novas tecnologias ocorreu, principalmente, através da aquisição de empresas em países desenvolvidos. Segundo os autores, este movimento das tecnologias para a matriz brasileira tem permitido a redução de custos e a melhoria na qualidade de produtos e processos, com benefícios até nas exportações a partir do Brasil.

Segundo dados coletados do relatório de investimento formulado pela Unctad $^{3}$, o Brasil, bem como as economias em desenvolvimento, apresentaram o mesmo comportamento relacionado às fusões e aquisições no período compreendido entre 2005 e 2011, experimentando um período de crescimento acelerado até o ano de 2008, no período pré-crise, e retomando o crescimento a partir de 2010. Apesar disso, o ano de 2008 representa para o Brasil o maior número de fusões e aquisições (F\&A) realizadas.

3 Conferência das Nações Unidas sobre Comércio e Desenvolvimento. 
Gráfico 5 - Número de F\&A transfronteiriças de 2005 a 2011

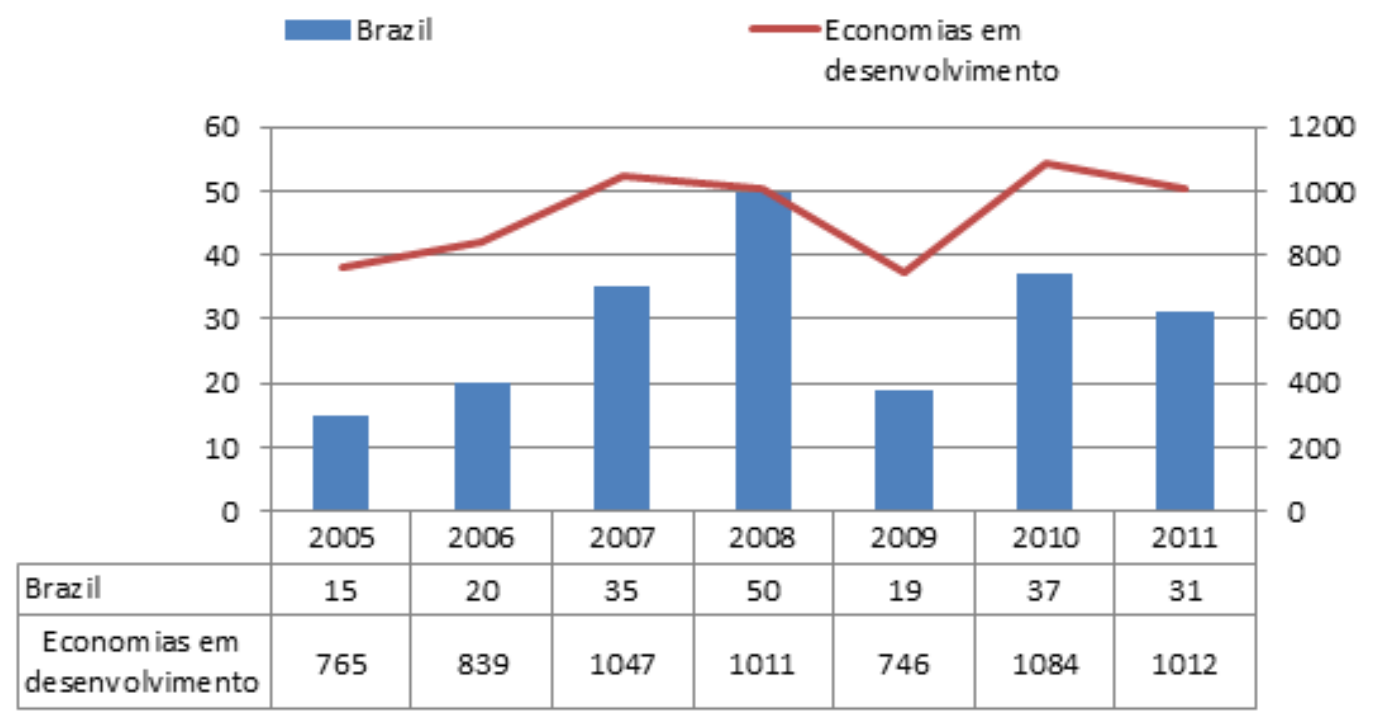

Fonte: Unctad (2012)

O apoio à internacionalização também ocorre em outros países, conforme Tabela 2. As políticas de incentivos à internacionalização são amplamente aplicadas pelos países desenvolvidos.

Tabela 2 - Apoio ao IED por países desenvolvidos

\begin{tabular}{|c|c|c|c|c|c|}
\hline \multicolumn{6}{|c|}{ Apoio ao investimento direto no exterior - Países desenvolvidos } \\
\hline & Informações & Missões & Des. do projeto & Financ. & Seg. e garantias \\
\hline Austrália & $\mathrm{x}$ & $\mathrm{x}$ & & & \\
\hline Áustria & $\mathrm{x}$ & $\mathrm{x}$ & $\mathrm{x}$ & & \\
\hline Bélgica & $\mathrm{x}$ & $\mathrm{x}$ & $\mathrm{x}$ & & \\
\hline Canadá & $\mathrm{x}$ & $\mathrm{x}$ & $\mathrm{x}$ & $\mathrm{x}$ & \\
\hline Dinamarca & $\mathrm{x}$ & $\mathrm{x}$ & & & \\
\hline Finlândia & $\mathrm{x}$ & $\mathrm{x}$ & $\mathrm{x}$ & $\mathrm{x}$ & $\mathrm{x}$ \\
\hline França & $\mathrm{x}$ & $\mathrm{x}$ & $\mathrm{x}$ & & \\
\hline Alemanha & $\mathrm{x}$ & $\mathrm{x}$ & $\mathrm{x}$ & $\mathrm{x}$ & $\mathrm{x}$ \\
\hline Itália & $\mathrm{x}$ & $\mathrm{x}$ & $\mathrm{x}$ & $\mathrm{x}$ & $\mathrm{x}$ \\
\hline Japão & $\mathrm{x}$ & $\mathrm{x}$ & $\mathrm{x}$ & $\mathrm{x}$ & $\mathrm{x}$ \\
\hline Países Baixos & $\mathrm{x}$ & $\mathrm{x}$ & $\mathrm{x}$ & $\mathrm{x}$ & \\
\hline Nova Zelândia & $\mathrm{x}$ & $\mathrm{x}$ & & & \\
\hline Noruega & $\mathrm{x}$ & $\mathrm{x}$ & $\mathrm{x}$ & $\mathrm{x}$ & $\mathrm{x}$ \\
\hline Portugal & $\mathrm{x}$ & $\mathrm{x}$ & $\mathrm{x}$ & & \\
\hline Espanha & $\mathrm{x}$ & $\mathrm{x}$ & $\mathrm{x}$ & $\mathrm{x}$ & \\
\hline Suécia & $\mathrm{x}$ & $\mathrm{x}$ & & & \\
\hline Suíça & $\mathrm{x}$ & $\mathrm{x}$ & $\mathrm{x}$ & $\mathrm{x}$ & $\mathrm{x}$ \\
\hline Reino Unido & & $\mathrm{x}$ & $\mathrm{x}$ & & \\
\hline EUA & $\mathrm{x}$ & $\mathrm{x}$ & $\mathrm{x}$ & $\mathrm{x}$ & $\mathrm{x}$ \\
\hline
\end{tabular}

Fonte: Unctad (1995). Extraído de Alem e Cavalcanti (2005). 
O apoio à internacionalização das empresas não é uma iniciativa exclusiva do Brasil ou dos países em desenvolvimento. $\mathrm{Na}$ economia internacional é generalizada a realização de incentivos utilizando-se de diversos instrumentos, como promovendo às empresas o acesso a informações através de estudos e pesquisas, organização de missões de investimento para o setor privado, desenvolvimento de projetos, financiamentos e realização de contratos de seguro e garantias para o investimento.

Além do incentivo, é comum também que o Estado participe como sócio de empresas transnacionais, classificadas como transnacionais estatais pela Unctad todas as empresas em que o governo possui $10 \%$ ou mais do poder de voto, ou é o maior acionista individual. Em 2010 havia pelo menos 650 estatais transnacionais, com mais de 8.500 filiais estrangeiras. Chama mais atenção o fato de que, entre as 100 maiores transnacionais do mundo, 19 possuem o caráter de estatal, e nos países em desenvolvimento são 28 entre as 100 maiores (UNCTAD, 2011).

Dentre as 30 maiores transnacionais estatais (baseado no valor total dos ativos estrangeiros) a Unctad sita as brasileiras Vale AS com 38\% dos ativos, $83 \%$ das vendas e 22\% dos empregos no exterior e a Petróleo Brasileiro AS (Petrobras) com $8 \%$ dos ativos, $25 \%$ das vendas e 10\% dos empregos no exterior (UNCTAD, 2011).

\subsection{Fundamentos e evidências dos resultados}

Em geral os impactos esperados pelo governo estão voltados para inovação, geração de empregos e exportações.

Dias, Caputo e Marques (2012, p. 176) concluíram com a pesquisa que:

Tendo em vista os resultados obtidos, pode-se concluir que os impactos positivos mais relevantes nas empresas brasileiras estudadas se deram na absorção de novas tecnologias e na capacitação do quadro de colaboradores. No caso dos impactos nas exportações, os resultados foram variados, e não houve maiores impactos na cadeia de suprimentos das empresas.

Resultados que em geral estão bem alinhados com as metas destacadas do governo de promover o crescimento com sustentabilidade, geração de empregos e distribuição de renda, fortalecer a inserção soberana internacional e elevar a competitividade sistêmica da economia, com inovação tecnológica.

Apesar dos resultados variados nas exportações brasileiras, analisando o resultado histórico recente, a economia apresenta um crescimento consistente, sendo realizado nos três níveis de fator agregado. 


\section{Gráfico 6 - Exportação brasileira por fator agregado em U\$ Milhões}

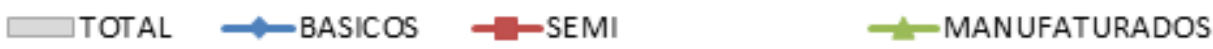

MANUFATURADOS

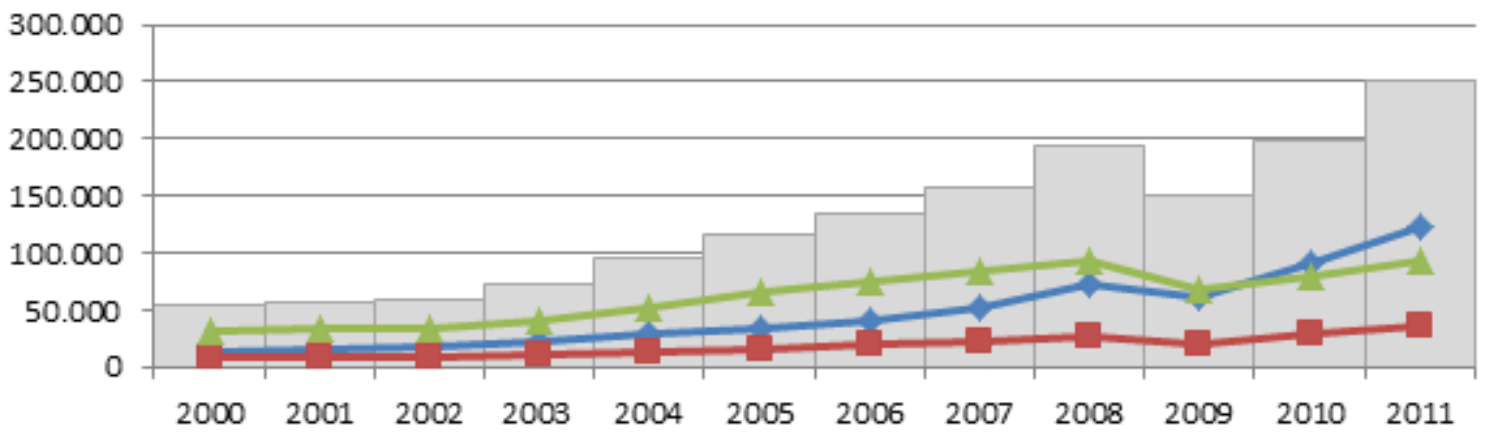

Fonte: Elaboração própria. Dados do MDIC.

Com relação à inovação, mais do que as aquisições visando a obtenção de tecnologias existentes, o país vem realizando um aumento relacionado ao investimento em P\&D. Segundo dados do ministério da Ciência e Tecnologia, o Brasil possuiu nos últimos anos um crescimento do valor de investimentos em pesquisa e desenvolvimento, conforme gráfico 7.

Gráfico 7 - Investimento brasileiro em $C \& T^{4}$, \% em relação PIB - Públicos Empresariais

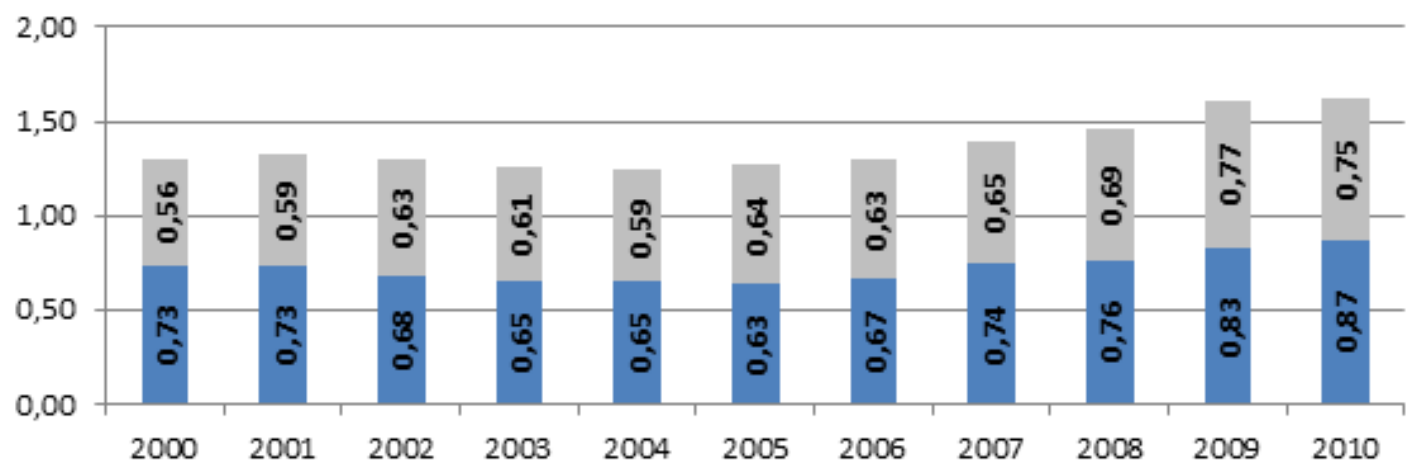

Fonte: Elaboração própria. Dados do Ministério da Ciência e Tecnologia.

Em termos absolutos, considerando o crescimento do PIB brasileiro e o percentual de dispêndio dos anos de 2007 e 2010, o Brasil cresceu 63,7\% no valor total investido.

Para Dias, Caputo e Marques (2012), existe uma relação positiva entre emprego e a internacionalização, onde a geração de empregos é afetada pela internacionalização das empresas porque com o investimento no exterior é gerado um aumento nas exportações de bens intermediários e também cria uma demanda por serviços que exigem elevados níveis de competência e gestão.

Caso os investimentos no exterior substituam os investimentos nacionais, haveria uma queda no número de empregos. Porém, existe a tendência de que,

4 Ciência e Tecnologia $(C \& T)=$ Pesquisa e Desenvolvimento $(\mathrm{P} \& D)+$ atividades e Técnicas correlatas (ACTC). 
com o sucesso da firma, o quadro seja revertido no longo prazo com a melhora da competividade da empresa. Neste sentido, haveria também uma troca de empregos relacionados a atividades produtivas e, portanto, mão de obra menos qualificada para empregos de caráter gerencial e mais qualificada.

$\mathrm{Na}$ Tabela 3, podemos constatar algumas estatísticas relacionadas às empresas transnacionais, comparando as 100 maiores do mundo com as 100 maiores dos países em desenvolvimento.

Tabela 3 - Comparação entre as 100 maiores transnacionais mundiais e dos países em desenvolvimento, 2009 e 2010

\begin{tabular}{|c|c|c|c|c|c|c|}
\hline $\begin{array}{r}\text { Est } \\
\text { Comparação entre } \\
\text { (B }\end{array}$ & $\begin{array}{l}\text { tística da } \\
\text { empresas } \\
\text { lhões de c }\end{array}$ & $\begin{array}{l}00 \text { maior } \\
\text { mundo e } \\
\text { res, milh }\end{array}$ & $\begin{array}{l}\text { ransnacion } \\
\text { economias } \\
\text { s de funcio }\end{array}$ & $\begin{array}{l}\text { ais não fir } \\
\text { m desenv } \\
\text { lários e p }\end{array}$ & $\begin{array}{l}\text { ceiras. } \\
\text { imento/ } \\
\text { ento) }\end{array}$ & transição. \\
\hline & $100 \mathrm{~m}$ & $\begin{array}{l}\text { res tran } \\
\text { mundiai }\end{array}$ & acionais & $\begin{array}{l}100 \mathrm{mai} \\
\text { econom }\end{array}$ & $\begin{array}{l}\text { s trans } \\
\text { em des } \\
\text { em trar }\end{array}$ & $\begin{array}{l}\text { cionais de } \\
\text { volvimen- } \\
\text { ção }\end{array}$ \\
\hline Indicador & 2009 & 2010 & Variação & 2009 & 2010 & Variação \\
\hline Ativos & & & & & & \\
\hline Estrangeiro & 7.147 & 7.495 & $4,9 \%$ & 997 & 1.068 & $7,1 \%$ \\
\hline Doméstico & 4.396 & 4.417 & $0,5 \%$ & 2.154 & 2.642 & $22,7 \%$ \\
\hline Total & 11.543 & 11.912 & $3,2 \%$ & 3.152 & 3.710 & $17,7 \%$ \\
\hline$\%$ de estrangeiro & $62 \%$ & $63 \%$ & $1,6 \%$ & $32 \%$ & $29 \%$ & $-9,0 \%$ \\
\hline Vendas & & & & & & \\
\hline Estrangeiro & 4.602 & 4.870 & $5,8 \%$ & 911 & 1.113 & $22,2 \%$ \\
\hline Doméstico & 2.377 & 2.721 & $14.5 \%$ & 1.003 & 1.311 & $30,7 \%$ \\
\hline Total & 6.979 & 7.590 & $8,8 \%$ & 1.914 & 2.424 & $26,6 \%$ \\
\hline$\%$ de estrangeiro & $66 \%$ & $64 \%$ & $-2,7 \%$ & $48 \%$ & $46 \%$ & $-3,5 \%$ \\
\hline Emprego & & & & & & \\
\hline Estrangeiro & 8.568 & 8.684 & $1,4 \%$ & 3.399 & 3.726 & $9,6 \%$ \\
\hline Doméstico & 6.576 & 6.502 & $-1,1 \%$ & 4.860 & 5.112 & $5,2 \%$ \\
\hline Total & 15.144 & 15.186 & $0,3 \%$ & 8.259 & 8.838 & $7,0 \%$ \\
\hline$\%$ de estrangeiro & $57 \%$ & $57 \%$ & $1,1 \%$ & $41 \%$ & $42 \%$ & $2,4 \%$ \\
\hline
\end{tabular}

Fonte: Unctad (2012)

Observando a tabela 3 podemos constatar que as empresas dos países em desenvolvimento, apesar de possuírem crescimento no ambiente externo, também sustentaram um crescimento no ambiente doméstico, fato que fundamenta a ação do governo não exportando empregos ou investimentos, mas criando firmas que crescem em ambos ambientes criando resultados melhores do que os anteriores a sua internacionalização.

Almeida (2007) também destaca que as empresas que investem no exterior podem aumentar o número de empregos no país de origem e que, além disso, podem garantir a manutenção das vagas existentes, já que as empresas, se mantendo restritas ao mercado nacional, poderiam sofrer com a concorrência. Estando menos competitivas ficariam enfraquecidas diante da competição 
internacional, podendo vir encerrar suas atividades ou a ser adquiridas por concorrentes.

Acrescenta-se então o caráter de sobrevivência das empresas brasileiras, onde as mais competitivas reduziriam sua vulnerabilidade externa em uma economia globalizada, em que o Brasil possui uma economia que desperta bastante interesse aos investidores estrangeiros em decorrência do seu mercado doméstico em expansão.

De acordo com relatório da UNCTAD, em 2010 o Brasil recebeu o quinto maior fluxo de IED, passando de um fluxo positivo de 26 bilhões de dólares para um total de 48 bilhões. Além disso, em pesquisas sobre prioridade para investimentos futuros, possui a quinta economia mais mencionada pelos investidores (UNCTAD, 2011).

Sobre as aquisições estrangeiras, Almeida (2007, p. 24) cita:

[...] na maioria dos episódios, a tendência, quando ocorre aquisição por parte de multinacionais estrangeiras, é de concentrar no país de origem do capital a fonte de desenvolvimento e de propriedade intelectual da tecnologia, relegando o papel da filial ao fornecimento de tecnologia adaptativa [...]

Com esta base, torna-se importante que as empresas brasileiras estejam fortificadas para se defender da concorrência internacional e sejam competitivas no mercado globalizado buscando assumir papel de liderança em seus setores de atuação. Este movimento irá garantir ao país a capacidade de geração e manutenção de empregos, desenvolvimento das empresas com economia de escala e escopo e capacidade de inovação.

Tabela 4 - Ranking brasileiro de internacionalização

\begin{tabular}{llc|llc}
\hline Posição & Empresa & Índice & Posição & Empresa & Índice \\
\hline 1 & JBS-Friboi & 0,538 & 16 & Artecola & 0,194 \\
2 & Gerdau & 0,516 & 17 & Embraer & 0,173 \\
3 & Stefanini IT Solutions & 0,464 & 18 & Camargo Corrêa & 0,165 \\
4 & Metalfrio & 0,452 & 19 & Marcopolo & 0,149 \\
5 & Marfrig & 0,444 & 20 & Agrale & 0,130 \\
6 & Ibope & 0,438 & 21 & Andrade Gutierrez & 0,123 \\
7 & Odebrecht & 0,424 & 22 & Natura & 0,119 \\
8 & Sabó & 0,363 & 23 & Cia Providência & 0,107 \\
9 & Magnesita & 0,361 & 24 & Itaú-Unibanco & 0,100 \\
10 & Tigre & 0,298 & 25 & América Latina Logística & 0,091 \\
11 & Susano Papel Celulose & 0,283 & 26 & Petrobras & 0,082 \\
12 & Vale & 0,278 & 27 & Minerva & 0,065 \\
13 & Weg & 0,246 & 28 & Bematech & 0,045 \\
14 & Brasil Foods & 0,238 & 29 & Banco do Brasil & 0,043 \\
15 & Ci\&T & 0,195 & 30 & BRQ IT Services & 0,040 \\
\hline
\end{tabular}

Fonte: FDC, Ranking das transnacionais brasileiras (2012). 
Com os objetivos apresentados, algumas empresas já buscaram sua inserção no mercado internacional. Segundo a Fundação Dom Cabral, o ranking das empresas brasileiras mais internacionalizadas (Tabela 4) é liderado pela JBS-Friboi e Gerdau, que receberam apoio do BNDES.

\subsection{Caso JBS-Friboi}

Empresa fundada em 1953, se desenvolveu e adquiriu alguns abatedouros trabalhando na área de frigoríficos, criação e abate de animais. Iniciou sua expansão internacional com a compra da unidade da empresa Swift, na Argentina, em 2005. Posteriormente adquiriu a matriz da Swift nos EUA e a unidade da Austrália (JBS, 2008).

Com o BNDES a empresa realizou em 2008 um empréstimo de $\mathrm{R} \$ 1,1$ bilhão de reais, em 2009 de $\mathrm{R} \$ 3,5$ bilhões, e em 2010 foram $\mathrm{R} \$ 200$ milhões. Os recursos foram utilizados. entre outros investimentos. nas aquisições. em 2009, da Pilgrm's Pride e da brasileira Bertin Ltda., tornando-a a maior companhia de produtos de origem animal do mundo, com um faturamento de $\mathrm{R} \$ 29$ bilhões ao ano. No Brasil, menor apenas que a empresas Petrobras e Vale (Veja, 2009).

Em 2011, a companhia registrou seu recorde de receita líquida, no valor de $\mathrm{R} \$ 61,8$ bilhões, o que a tornou líder mundial em produção de proteína animal e a segunda maior multinacional privada de origem brasileira. Com um total de 135 mil empregados (59 mil no Brasil), a empresa é a única do setor que atua nos três principais países produtores do mundo (Brasil, EUA e Austrália) e possui consumidores em mais de 140 países. É líder no mercado de carne bovina e ovina, e segundo maior produtor em carne de frango. Além da sua atuação em carnes in natura, atua em segmentos de maior valor agregado com diversas marcas (JBS, 2011).

\subsection{Caso Gerdau}

Empresa fundada em 1901, iniciou suas atividades como fábrica de pregos, se desenvolveu no mercado brasileiro, e em decorrência de dificuldades de acesso a matéria-prima, realizou sua entrada no ramo de siderurgia com a compra da Siderúrgica Riograndense (Athia e Dalla Costa, 2009).

O primeiro financiamento realizado com o BNDES ocorreu em 1975, com o objetivo de instalação do laminador em Sapucaia do Sul. Iniciou sua internacionalização em 1980 através da aquisição da siderúrgica uruguaia Laisa. Um novo passo ocorreu em 1989 com a aquisição da siderúrgica canadense Courtice Steel Inc., e a partir de então, a firma realizou sua expansão principalmente na América do Sul e do Norte, intensificando este movimento ainda mais nos últimos 5 anos. Com estes movimentos realizou um crescimento sustentado de 14,6\% ao ano entre 1997 e 2010 (FDC, 2011).

Em 2009, teve aprovação do BNDES em um limite de crédito de $\mathrm{R} \$ 1,5$ bilhão com o objetivo de investimentos até 2013 em reforma e modernização em diversas áreas, ampliação da capacidade de produção de determinadas linhas de 
produtos, investimentos em logística e geração de energia e projetos ambientais e de sustentabilidade (BNDES, 2009).

No ano de 2011, a empresa assim, como a JBS, registrou seu recorde em volume de vendas atingindo a receita líquida de $\mathrm{R} \$ 35,4$ bilhões, com um crescimento de $10 \%$ sobre o volume do ano anterior. É a maior produtora de aços longos da América Latina e possui plantas de produção em 14 países e um total de 45 mil funcionários ( 28 mil no Brasil). Com a perspectiva de um aumento no consumo dos mercados em que atua, a firma pretende realizar $\mathrm{R} \$ 1$, 3 bilhões de investimentos entre os anos de 2012 e 2016 (Gerdau, 2011).

\section{Conclusões}

A partir da análise elaborada neste artigo, pode-se verificar que o governo brasileiro vem exercendo uma posição mais ativa sobre o mercado, caracterizando uma nova fase no desenvolvimento econômico brasileiro que está ligada ao crescimento de empresas em um ambiente globalizado.

Como principais objetivos para o apoio de criação de grandes empresas, o governo possui a intenção de: tornar as firmas mais competitivas, aumentar o número de empregos, aumentar o número de empregos de alta qualificação, incentivar as inovações e o desenvolvimento de tecnologias e aumentar o nível de exportações.

A criação de grandes grupos, aliada aos objetivos apresentados pelo Estado, nos remete à internacionalização das empresas brasileiras e seus investimentos em busca de uma posição forte no mercado internacional, políticas semelhantes ocorrem em diversos países desenvolvidos e em desenvolvimento.

Para alcançar estes objetivos, o Estado se utilizou do BNDES, banco que possui grande responsabilidade com a sociedade brasileira dada suas fontes de recursos. Conforme apresentado, o banco vem intensificando sua participação na economia nos últimos anos, principalmente no período de 2008 a 2011, realizando em 2011 um total de 139 bilhões de reais de desembolsos. Se comparado a 2001 , ano em que registrou 25 bilhões de reais, obteve um crescimento de $444 \%$ no período de 10 anos.

Foi possível constatar, através dos dados analisados, que existiu neste período de 2008 a 2011 um crescimento paralelo das exportações brasileiras nos três níveis de fator agregado.

No que tange à inovação, as empresas nacionais buscaram aquisições e fusões para conquistar acesso a novas tecnologias, além de estarem realizando maiores investimentos em ciência e tecnologia. O país investiu em 2010 um valor $63,7 \%$ maior do que investiu no ano de 2007 , sendo que o aumento nos últimos anos ocorreu tanto por parte do setor público quanto do privado.

Sobre a geração de empregos, foi constatado, através de pesquisas com as empresas brasileiras internacionalizadas e os dados das 100 maiores transnacionais, que o investimento externo possui o potencial de geração de empregos no ambiente doméstico, além de aumentar a qualificação dos cargos nacionais disponíveis. 
Além dos benefícios que o Estado busca, existe outro ponto positivo no apoio do BNDES, ligado à sobrevivência das firmas nacionais. De acordo com a teoria apresentada, existe uma tendência à concentração. Somado a isto, temos a atratividade do Brasil, que recebeu o $5^{\circ}$ maior fluxo de investimentos do mundo no ano de 2011, e a tendência das empresas estrangeiras centralizarem no país de origem a fonte de desenvolvimento e de propriedade intelectual.

Individualmente, as nacionais mais internacionalizadas no ano de 2012, JBS-Friboi e Gerdau, receberam apoio do BNDES e passaram por um período de grande movimento relacionado ao investimento externo, fusões e aquisições, e conquistaram posições relevantes no mercado, recordes em receita líquida e volume de vendas no ano de 2011.

Em linhas gerais, é possível afirmar que os resultados obtidos na economia estão bem alinhados as propostas do governo e do BNDES como banco nacional do desenvolvimento econômico e social.

\section{Referências}

Alem, A. C.; Cavalcanti, C. E. (2005). "O BNDES e o apoio à internacionalização das empresas brasileiras: algumas reflexões.” Revista do BNDES, vol. 12 (24); p. 4376.

Alem, A. C.; Madeira, R. (2010). “O BNDES em um BRASIL em Transição. Internacionalização e Competitividade: A importância da criação e empresas multinacionais brasileiras.” BNDES; p. 39-58.

Almeida. A. (2007). Internacionalização de empresas brasileiras: Perspectivas e riscos. Rio de Janeiro, RJ: Editora Elsevier.

Athia, F.; Dalla Costa; A. (2009). "Grupo Gerdau: uma análise do crescimento produtivo e da expansão internacional.” Economia \& Tecnologia-Publicação da Universidade Federal do Paraná, vol. 16 (5); p. 131-142.

BNDES. O Banco Nacional do Desenvolvimento. "BNDES aprova limite de crédito de R\$ 1,5 bilhão para Grupo Gerdau.” URL [on-line]: < http://www.bndes.gov. br/SiteBNDES/bndes/bndes_pt/Institucional/Sala_de_Imprensa/Noticias/2009/ Industria/20090707_gerdau.html> Acesso em: 01/02/2013.

BNDES. “O BNDES em números. Relatório Anual de 2011.” URL [on-line]: < http:// www.bndes.gov.br/SiteBNDES/bndes/bndes_pt/Hotsites/Relatorio_Anual_2011/ Capitulos/o_bndes_em_numeros/indicadores_operacionais_desembolso/>. Acesso em: 19/12/2012.

BNDES. O Banco Nacional do Desenvolvimento. URL [on-line]: <www.bndes.gov.br >. Acesso em: 19/12/2012.

Dias, A. M.; Caputo, A. C.; Marques, P. M. (2012). "Motivações e impactos da internacionalização de empresas: um estudo de múltiplos casos na indústria brasileira." Revista do BNDES, n. 38, p. 139-180.

Fundação Dom Cabral (FDC). "Ranking das Transnacionais Brasileiras 2012: Os benefícios da internacionalização.” URL [on-line]: <http://www.fdc.org.br>. Acesso em: 07/02/2013. 
Gerdau. "Relatório Anual 2011.” URL [on-line]: <http://www.gerdau.com.br/ relatoriogerdau/2011/ra-br/download.asp>. Acesso em: 01/02/2013.

Instituto Alvorada. "O papel do Estado na formação de grandes conglomerados nacionais.” URL [on-line]: <http://institutoalvorada.org/o-papel-do-estado-naformac\%CC\%A7a\%CC\%83o-de-grandes-conglomerados-nacionais > . Acesso em: $10 / 12 / 2012$.

JBS. "Relatório Anual 2008." URL [on-line]: <http://www.jbs.com.br/ri/>. Acesso em: 10/02/2013.

JBS. "Relatório Anual 2011." URL [on-line]: <http://www.jbs.com.br/ri/>. Acesso em: 10/02/2013.

Ministério da Ciência, Tecnologia e Inovação. "Dispêndio Nacional em Ciência e Tecnologia de 2000 a 2010.” URL [on-line]: < http://www.mct.gov.br/index.php/ content/view/9058.html\&usg=ALkJrhhQOc6Lp7IwhvOhK_d0jrLmonHHyA>. Acesso em: 18/01/2013.

Ministério do Desenvolvimento, Indústria e Comércio Exterior (MDIC). "Exportação Brasileira por Fator Agregado de 1964 a 2011.” URL [on-line]: <http:// www.desenvolvimento.gov.br/sitio/interna/interna.php?area=5\&menu= 1846\&refr=608>. Acesso em: 05/02/2013.

Ministério do Planejamento. "Orientação Estratégica do Governo. Brasília, junho de 2007." URL [on-line]: <http://www.sigplan.gov.br/download/ avisos/001mensagempresidencial_internet>. Acesso em: 09/12/2012.

Nelson, R. R.; Winter, Sidney G. (2005). Uma teoria evolucionária da mudança econômica. Campinas, SP: Editora Unicamp.

Porter, M. (1999). Competição: Estratégias competitivas essenciais. Rio de Janeiro, RJ: Editora Elsevier.

Possas, M. L. (1990). Estruturas de Mercado em Oligopólio. São Paulo, SP: Editora: Hucitec.

Ramalho Y.; Café, S. L.; Costa, G. (2010). "O BNDES em um Brasil em Transição. Planejamento corporativo 2009-2014.” BNDES, p. 93-106.

UNCTAD. "World Investment Report (WIR) 2011: NON-EQUITY MODES OF INTERNATIONAL PRODUCTION AND DEVELOPMENT.” New York and Geneva, United Nations, 2011. URL [on-line]: <http://www.unctad.org>. Acesso em: 18/01/2013.

UNCTAD. "World Investment Report (WIR) 2012: TOWARDS A NEW GENERATION OF INVESTMENT POLICIES.” New York and Geneva, United Nations, 2011. URL [on-line]: <http://www.unctad.org>. Acesso em: 18/01/2013.

UNCTAD. UNCTADSTATS. New York and Geneva, United Nations, 2011. DURL [on-line]: <http://unctadstat.unctad.org>. Acesso em: 18/01/2013.

Veja. "A Proteína do agronegócio.” URL [on-line]: <http://veja.abril.com.br/ 230909/ proteina-agronegocio-p-088.shtml> . Acesso em: 18/01/2013. 